\title{
Randomised Controlled Trial To Investigate The Effectiveness of The Self-Management After Radiotherapy (SMaRT) Intervention To Ameliorate Lower Urinary Tract Symptoms in Men Treated for Prostate Cancer
}

Sara Faithfull ( $\square$ s.faithfull@surrey.ac.uk)

University of Surrey https://orcid.org/0000-0002-7951-0243

Jane Cockle-Hearne

University of Surrey

Agnieszka Lemanska

University of Surrey

\section{Sophie Otter}

Royal Surrey County Hospital NHS Trust: Royal Surrey NHS Foundation Trust

Simon Skene

University of Surrey

\section{Research Article}

Keywords: Prostate neoplasm, lower urinary tract symptoms, self-management, radiotherapy, late effects, survivorship

Posted Date: October 21st, 2021

DOI: https://doi.org/10.21203/rs.3.rs-873473/v1

License: (c) This work is licensed under a Creative Commons Attribution 4.0 International License. Read Full License 


\section{Abstract \\ Purpose}

To evaluate the effectiveness of the self-management after radiotherapy (SMaRT) intervention to improve urinary symptoms in men with prostate cancer.

\section{Methods}

The randomised controlled trial (RCT) recruited men from one radiotherapy centre in the UK after curative radiotherapy or brachytherapy and moderate urinary symptoms defined as the International Prostate Symptom Score (IPSS) $\geq 8.63$ men were randomised either to SMaRT, a 10-week self-management intervention including group support, education, pelvic floor muscle exercises, or care-as-usual. The primary outcome was the IPSS at 6 months. Secondary outcomes were IPSS at 3 months, and International Continence Society Male Short Form (ICS), European Organisation for Research and Treatment of Cancer Quality of Life prostate scale (EORTC QLQPR25), EORTC QLQ-30 and Self-Efficacy for Symptom Control Inventory (SESCI) at 3 and 6 months. Analysis of covariance (ANCOVA) was used to analyse the effect of the intervention.

\section{Results}

SMaRT did not improve urinary symptoms as measured by IPSS at 6 months. The adjusted difference was -2.5 [ $95 \% \mathrm{Cl}-5.0$ to 0.0$], p=0.054$. Significant differences were detected at 3 months in ICS voiding symptoms $(-1.1$ [-2.0 to -0.2$], p=0.017)$, ICS urinary incontinence $(-1.0[-1.8$ to -0.1$], p=0.029)$ and SESCI managing symptoms domain (13.5 [2.5 to 24.4], $p=0.017$ ). No differences were observed at 6 months.

\section{Conclusions}

SMaRT provided short-term benefit in urinary voiding and continence, and helped men manage symptoms but was not effective long-term. Face-to-face and supervised approaches may provide more benefit.

\section{Introduction}

Prostate cancer ( $\mathrm{PCa}$ ) is one of the most commonly diagnosed cancers in men and accounts for $26 \%$ of all new UK male cancer cases (1). It is estimated that 1.3 million men worldwide are diagnosed per year (2) and with earlier detection and better treatments more men are living with and beyond a PCa diagnosis (3). Although quantity of life has improved, quality of life may be reduced compared to those without cancer because of side effects after treatment (4). Improving symptom management post prostate cancer treatment is therefore a priority for research and clinical practice (5).

Quality-of-life in men living with and beyond PCa can be impacted by long-term side-effects post treatment, with prevalence of erectile dysfunction $(87 \%$,) urinary symptoms $(20 \%)$ and bowel disturbance $(14 \%)$ occurring up to 12 years after $\mathrm{PCa}$ treatment (6). Two years after initial PCa treatment distress in relation to urinary problems was experienced by $7 \%$ of men after radical prostatectomy and $11-16 \%$ of men after radiotherapy (6). In a USA 
study of Medicare claims the adjusted risk of grade 2-4 (moderate to severe) urinary symptoms after radiotherapy for PCa was OR 2.49 (95\% Cl: 2 to 3.11) times that of men without treatment at 10 years (7). Additionally a recent UK population study exploring self-reported symptoms and quality of life in 13,097 men 18-42 months post PCa diagnosis, found $13.5 \%$ of men reported moderate to severe bother with urinary symptoms and those with urinary bother were more likely to have poorer mental health OR 2.89 (2.54 to 3.27 ) and severe psychological distress OR 3.69 (3.12-4.38) (8). Whilst interventions are available for acute symptoms, long term urinary symptoms after PCa are often poorly addressed reducing men's ability to socialise and impacting men's daily activities (9).

Regardless of the type of radiotherapy (external beam radiotherapy or brachytherapy) the close proximity of the genitourinary tract to the prostate means urinary symptoms are relatively common during and shortly after radiotherapy (10). Acute urinary symptoms are often transient, long term symptoms can continue for 3-6 months, and late side-effects can be newly occurring up to 2 years after external beam radiotherapy (11). Adverse effects are more severe in those who are older, have poorer physical function and greater urinary symptoms at baseline (12-14). External beam radiation (EBRT) utilises high-energy photon beams and is shaped and conformed to the profile of the prostate gland such as conformal radiotherapy (CFRT) or delivered through intensity-modulated radiotherapy (IMRT) minimising surrounding normal tissue damage (15), however lower doses of radiation can cover a wider field across the pelvis impacting on additional pelvic structures.

Radiation alters bladder contractility through the effect of ionisation on the mucosal-detrusor communication, which impacts on stability of the bladder and voiding symptoms (16). Urothelial cells are very radiosensitive and pelvic radiotherapy has both direct as well as bystander affects that result in inflammation, vascular damage and fibrosis (17) causing urinary frequency, bleeding and urinary obstruction (18). Pelvic floor muscle structures are also affected by radiation with changes in muscle activity and contractility that all impact on urinary function (19). There is a paucity of studies on conservative intervention approaches for radiation induced urinary symptoms (10). Dieperink et al (20) tested the efficacy of a nurse-physiotherapist intervention, including pelvic floor muscle exercises (PFME), for men during and after external beam radiotherapy. Men in the intervention compared to men in the care-as-usual, showed significant improvements in urinary and hormonal symptoms at 20 weeks post intervention and improved men's physical quality-of-life. However, one-to-one intervention can be time consuming, require more clinical resources than group interventions and not provide opportunity for peer support that can be found in self-management programs. Self-management support ensures people develop the confidence and skills they need to look after their ongoing physical and mental health (21).

Systematic reviews of the effectiveness of cancer self-management support for cancer survivors have consistently led researchers to call for focused, disease-specific and patient targeted programmes (22-24). Previous to the study reported here, our feasibility work found that an augmented self-management intervention including coaching, bladder retraining and PFME instruction delivered at 3-6 months post radiotherapy treatment for PCa, was feasible within the clinical setting (25). We hypothesised that in comparison with care-asusual, at six months post intervention men who took part in the SMaRT intervention would report significantly less urinary symptoms, have better symptom-related quality-of-life, less emotional distress and improved confidence to deal with PCa and its associated problems.

\section{Materials And Methods}


This study was a two-armed, parallel-group randomised controlled trial. Participants were from one radiotherapy unit, serving four hospitals within NHS England, UK. They had received external beam radiotherapy (EBRT) with neo-adjuvant or adjuvant androgen deprivation therapy (ADT) or low dose-rate brachytherapy (BT).

\section{Setting and participants}

Men starting EBRT were asked to participate in the trial during on-treatment physician review. BT patients were invited by letter from their clinical nurse specialist (CNS) after treatment. All participant consent forms were returned by post. To allow for recovery of acute symptoms after treatment, men were screened for urinary symptoms at 3 months after EBRT with the International Prostate Symptom Score (IPSS) questionnaire and 6 months after BT. Men with IPSS scores $\geq 8$ (moderate to severe symptoms) i.e., 70 of the 137 men, were entered into the trial and after baseline assessment they were randomised to receive either the SMaRT intervention plus care-as-usual, or only care-as-usual. Care-as-usual was defined as hospital appointments for surveillance and symptom management with the clinical oncologist and/or telephone support with the CNS. Eligibility criteria are summarised in Table 1. Men were stratified for type of radiotherapy treatment (EBRT vs BT) and randomisation was provided by a registered clinical trials unit. To ensure balance in group sizes, participants were randomly allocated to control or intervention in blocks of 12. Information about treatment, medication, TNM staging, and comorbidity was obtained from the medical records.

Table 1

SMaRT study eligibility criteria

\section{Inclusion}

Patients who had:

- Locally confined prostate cancer disease (up to stage T3BNO)

- Received neoadjuvant hormonal therapy (to control for standardised practice as recommended in the EAU Guidelines).

- Completed external beam radiotherapy three to four months prior to the intended commencement of the intervention.

- Or LDR brachytherapy six months prior to the intended commencement of the intervention.

- Moderate to severe urinary symptoms defined as a score of $\geq 8$ on the International Prostate Symptom Score (IPSS).

- Sufficient understanding of written and spoken English.

\section{Exclusion}

Patients who had:

- A urinary tract infection.

- A current psychiatric referral.

- A current referral for memory issues/ever been referred to a memory clinic/taking prescribed medication to help with memory.

- Required an interpreter. 


\section{Intervention}

The SMaRT intervention was based on the framework that to be effective, self-management must address three core tasks namely, medical management (taking medications and treatment exercises), role management (adapting lifestyle or life roles) and emotional management (26). Having the confidence or belief to perform a given course of action is also a key mechanism whereby self-management can lead to changes in health behaviours and outcomes (26). To reflect this, our intervention also aimed to promote participant modelling, a key requirement for enhancing self-efficacy (27). A theory-based, 15-minute motivational film was produced by the research team and shown in the first group session to promote group dialogue and peer support (28).

The programme was delivered by an experienced nurse trained in teaching PFME and self-management techniques. PFME were taught both standing, sitting and laying down with 30 minutes of muscle strength training which included muscle endurance and strength with 10 repetitions for each muscle group for both. Discussions were conducted on bladder retraining techniques, fluid management, medication as well as the impact of symptoms on their wellbeing. Modules ran over 10 weeks and comprised four small group sessions (with 5/6 participants), one individual session with the CNS, and two telephone sessions with the CNS (Table 2.) This was followed by four months of at-home self-management. The group sessions were provided within a community leisure facility; face-to-face individual sessions were conducted at a clinical centre. Information booklets were provided in all the group sessions and set homework was discussed at the following group session. Outcome measures were completed at three time points: two weeks prior to the intervention at randomisation (baseline), 3 months and 6 months. 
Table 2

Self-Management after Radiation Therapy (SMaRT) intervention and assessment time points

\begin{tabular}{|c|c|c|}
\hline Timeline & Session & Content \\
\hline \multicolumn{3}{|c|}{ Week 0 and - 1 Baseline Assessment (T1) } \\
\hline \multirow{6}{*}{$\begin{array}{l}\text { Week 1: } \\
90 \\
\text { minutes }\end{array}$} & \multirow[t]{6}{*}{ Group session } & Introduction to the programme. \\
\hline & & Short motivational peer support film \\
\hline & & Exploration of experiences and emotional impact of prostate cancer \\
\hline & & Demonstration and group practice of PFME \\
\hline & & Information provision \\
\hline & & Promotion of daily home exercise (homework) \\
\hline \multirow{6}{*}{$\begin{array}{l}\text { Week 2: } \\
40 \\
\text { minutes }\end{array}$} & \multirow{6}{*}{$\begin{array}{l}\text { Individual face-to- } \\
\text { face session }\end{array}$} & One-to-one discussion \\
\hline & & Individual problem assessment and goal setting \\
\hline & & Review of 7-day bladder diary \\
\hline & & $\begin{array}{l}\text { Guidance and information around other pelvic late effects (bowel and } \\
\text { sexual issues) }\end{array}$ \\
\hline & & Addressing personal and relationship issues \\
\hline & & Physical assessment and personal training for PFME \\
\hline \multirow{4}{*}{$\begin{array}{l}\text { Week 3: } \\
60 \\
\text { minutes }\end{array}$} & \multirow[t]{4}{*}{ Group session } & Group discussion of problem solving and progress \\
\hline & & $\begin{array}{l}\text { Reinforcement and practice of PFME techniques Introduction of bladder- } \\
\text { retraining techniques }\end{array}$ \\
\hline & & Information of managing lower urinary tract medications \\
\hline & & Information on sexual dysfunction, bowel problems and ADT \\
\hline \multirow{4}{*}{$\begin{array}{l}\text { Week 5: } \\
60 \\
\text { minutes }\end{array}$} & \multirow[t]{4}{*}{ Group session } & Sharing experiences and tips \\
\hline & & Reinforcement and group practice of PFME \\
\hline & & Bladder retraining \\
\hline & & Evaluating progress and reviewing goals \\
\hline $\begin{array}{l}\text { Week 6: } \\
20 \\
\text { minutes }\end{array}$ & $\begin{array}{l}\text { Individual } \\
\text { telephone review }\end{array}$ & Reviewing personal goals, motivation and exploration of personal issues. \\
\hline
\end{tabular}




\begin{tabular}{|c|c|c|}
\hline Timeline & Session & Content \\
\hline Week 7: & Group session & Longer-term planning and goals \\
\hline \multirow{4}{*}{$\begin{array}{l}60 \\
\text { minutes }\end{array}$} & & Reinforcement and group practice of PFME \\
\hline & & Discussion on how to maintain PFME \\
\hline & & Management techniques for long term symptoms \\
\hline & & Open discussion and feedback \\
\hline \multicolumn{3}{|c|}{ Week 8 Interim Assessments (T2) } \\
\hline $\begin{array}{l}\text { Weeks } \\
10\end{array}$ & $\begin{array}{l}\text { Telephone follow- } \\
\text { up }\end{array}$ & $\begin{array}{l}\text { Reviewing personal goals, motivation and exploration of personal } \\
\text { symptoms and follow-up plan for the individual. }\end{array}$ \\
\hline \multicolumn{3}{|c|}{ Week 25 Final Assessments (T3) } \\
\hline \multicolumn{3}{|c|}{ Abbreviations: PFME Pelvic Floor Muscle Exercises } \\
\hline
\end{tabular}

The primary outcome was the sum score of urinary symptoms measured by the IPSS at 6 months. Secondary outcomes were: IPSS at 3 months and urinary symptoms measured by the International Continence Society Male Short Form questionnaire (ICSmaleSF); symptom-related quality-of-life measured by the European Organisation for Research and Treatment of Cancer Quality-of-Life scale (EORTC QLQ-PR25), emotional distress measured by the EORTC Quality-of-Life Questionnaire (EORTC QLQ-30); self-efficacy measured by the SelfEfficacy for Symptom Control Inventory (SESCl) at 3 and 6 months.

IPSS self-report questionnaire was used as the primary outcome measure as it is a commonly used clinical assessment tool to measure the degree of LUTs and impact on quality of life with seven questions relating to voiding including: emptying, frequency, intermittency, urgency, weak stream, straining and nocturia. A score of 7 or less is mildly symptomatic, 8-19 is moderately symptomatic and scores from $20-35$ indicate severe symptoms (29).

ICSmaleSF a more detailed urinary symptom assessment tool was used to explore urinary functioning and included two distinct LUTs components, voiding (ICSmaleVS) and incontinence (ICSmaleIS). A simple additive score was calculated by adding the 5 items in ICSmaleVC and 6 for ICSmalelS. The Cronbach's alpha coefficient for this tool were high at 0.76 for voiding and 0.78 for incontinence symptoms against other measures (30). Both IPSS and ICSmaleSF are generic LUTs measures and not cancer specific, therefore we included more specific prostate cancer measures.

EORTC QLQ-PR 25 is designed for use amongst men with localised and metastatic prostate cancer. Includes subscale assessing urinary symptoms, bowel symptoms, treatment-related symptoms and sexual functioning. Cronbach's alpha for urinary and sexual scales $0.70-0.86$, for other scales $<0.70$ (31).

EORTC QLQ-C30 for assessing the quality-of-life of cancer patients which is a reliable and valid measure of quality-of-life of cancer patients in multicultural clinical research settings. Contains five functional scales, global quality-of-life scale and general symptom scales. Cronbach's alpha across scales $0.52-0.89$. This tool is used extensively in clinical research studies worldwide and in our feasibility study (25). 
SESCl questionnaire measures three dimensions: i) confidence to perform daily activities; ii) confidence to cope with urinary symptoms; and iii) confidence to manage (change) urinary symptoms. Cronbach's alpha for total scale 0.97 Cronbach's alpha for each subscale 0.94 (32).

\section{Sample size calculations and statistical methods}

Based on our feasibility study data, a two-sided significance level of 5\%, and 85\% power, a sample size of 21 evaluable participants per arm was considered sufficient to detect a mean difference of change in IPSS score of 4 points between intervention and control, considered clinically significant. The calculation assumed a standard deviation for change from baseline in IPSS scores of 4.2. To account for possible attrition (withdrawal/loss-tofollow-up) of up to $30 \%$, randomisation was planned to include a minimum of 60 participants.

The primary statistical analysis was undertaken using regression methods (analysis of variance, ANCOVA) to estimate the difference in IPSS scores between groups (intervention vs control) at six months from randomisation together with a two-sided 95\% confidence interval, adjusting for baseline IPSS scores and type of radiotherapy which was included as covariate. Where $95 \%$ confidence intervals (Cls) do not span zero, the results would be regarded as significant.

For secondary outcomes, the differences between the two groups (intervention vs control) were analysed using regression estimates and $95 \%$ Cls obtained through the ANCOVA approach outlined above at both the three and six-months follow-up points.

The analysis was performed as a complete case analysis. To retain the validity of the randomisation, analyses were undertaken according to the intention-to-treat principle and included all consented and randomised patients for whom outcomes were available.

\section{Results}

\section{Recruitment and study flow}

Of 355 invited patients, 137 (39\%, 137/355) consented. At screening, 70 consented patients $(51 \%, 70 / 137)$ continued to have moderate/severe urinary symptoms (IPSS score $\geq 8$ ) at 3 to 6 months post treatment. 63 men were randomised, 31 to receive the SMaRT intervention plus usual care and 32 care-as-usual. Three participants in the intervention group withdrew prior to the first session due to travel issues, one control and one intervention participant were lost to follow-up, one intervention participant had missing IPSS scores at final assessment and one control participant died. Figure 1 shows the CONSORT diagram of recruitment and participant flow. Twentyeight participants started the intervention; attendance at sessions was $86.2 \%$ (mean number of sessions attended 5.45; SD 1.96); study attrition was 9.5\% (6/63), excluding follow-up telephone sessions. Overall, telephone follow-up attendance was 63\% (attendances: 35/56).

\section{Baseline characteristics}

Demographic, disease and treatment characteristics and screened IPSS scores for the SMaRT and care-as-usual groups at baseline are given in Table 3. The SMaRT group participants were slightly younger than the care-asusual group, socioeconomic status was high in both groups. Baseline median age score for the sample was 71 
(IQR 67 to 76$)$. One or more comorbidities was common with more than $33.3 \%(21 / 63)$ having 2 or more conditions and $25.3 \%$ (16/63) 3 or more conditions. Stage III disease was in $30.1 \%(19 / 63)$ of men and disease stage was similarly distributed across groups. More men in the care-as-usual group had received ADT $68.7 \%$ $(22 / 32)$ as part of neoadjuvant therapy. Men receiving EBRT made up $77.7 \%(49 / 63)$ of the sample. More men in the SMaRT group received brachytherapy $25.8 \%$ (8/31) compared to care-as-usual of $19.4 \%(6 / 32)$. Over $53 \%$ $(34 / 63)$ of the men in the study were taking long term medication for LUTS. Radiotherapy treatment was adjusted for in the multivariate analysis due to the uneven distribution within the groups. 
Table 3

Baseline characteristics by randomisation group

$\begin{array}{lll}\text { SMaRT Group } n=31 \quad \text { CAU Group } n=32 & \begin{array}{l}\text { Total } \\ (N= \\ \end{array} \\ & 63)\end{array}$

Age in years:

Mean (SD)

$69.9(7.3)$

$72.2(6.7)$

71.1

(7.1)

Median (IQR)

$69(65.0-74.0)$

$73(68.3-77.0)$

71

(67-

76)

IPSS at baseline:

Mean (SD)

$13.2(4.0)$

$13.9(5.1)$

13.6

Median (IQR)

$12(10-17)$

$12.5(10.2-16.8)$

12

Social status: EIMD Quintiles: $\mathrm{n}(\%)$

1 Most Deprived

2

3

4

5 Least Deprived

Missing

Body Mass Index (BMI) Kgm²: n (\%)

$<18.5$

$18.5-24.9$

25-29.9

$>30$

Missing

Comorbidities: n (\%)

$0 \quad 0 \quad 0$

$4(12.9) \quad 0$

4

$1(3.2)$

5 (15.6)

6

4 (12.9)

8 (25.0)

12

$22(71.0)$

19 (59.4)

41

$0 \quad 1(3.1)$

1

$\begin{array}{ll}1 \\ (3.1) & (1.5)\end{array}$

$1(3.2)$

0 1

$3(9.6)$

$1(3.1)$

4

12

5 (16.1)

$7(21.8)$

4

$1(3.2)$

$3(9.3)$

21(67.7)

$21(65.6)$ 


\begin{tabular}{|c|c|c|c|}
\hline & SMaRT Group n = 31 & CAU Group $n=32$ & $\begin{array}{l}\text { Total } \\
(\mathrm{N}= \\
63)\end{array}$ \\
\hline None & $1(3.2)$ & $3(9.3)$ & $\begin{array}{l}4 \\
(6.3)\end{array}$ \\
\hline 1 & $5(16.1)$ & $4(12.5)$ & $\begin{array}{l}9 \\
(14.2)\end{array}$ \\
\hline 2 & $9(29.0)$ & $12(37.5)$ & $\begin{array}{l}21 \\
(33.3)\end{array}$ \\
\hline 3 & $10(32.3)$ & $6(18.7)$ & $\begin{array}{l}16 \\
(25.3)\end{array}$ \\
\hline 4 & $4(12.9)$ & $1(3.1)$ & $\begin{array}{l}5 \\
(7.9)\end{array}$ \\
\hline 5 & $2(6.5)$ & $4(12.5)$ & $\begin{array}{l}6 \\
(9.5)\end{array}$ \\
\hline 6 & 0 & $1(3.1)$ & $\begin{array}{l}1 \\
(1.5)\end{array}$ \\
\hline $8-9$ & $3(9.7)$ & $3(9.3)$ & $\begin{array}{l}3 \\
(4.7)\end{array}$ \\
\hline Missing & 0 & $1(3.1)$ & $\begin{array}{l}1 \\
(1.5)\end{array}$ \\
\hline \multicolumn{4}{|l|}{ Stage of disease: $\mathrm{n}(\%)$} \\
\hline I & $9(29.0)$ & $8(25)$ & $\begin{array}{l}17 \\
(26.9)\end{array}$ \\
\hline II & $7(22.5)$ & $11(34.3)$ & $\begin{array}{l}18 \\
(28.5)\end{array}$ \\
\hline III & $10(32.2)$ & $9(28.5)$ & $\begin{array}{l}19 \\
(30.1)\end{array}$ \\
\hline Missing & $5(16.1)$ & $4(12.5)$ & $\begin{array}{l}9 \\
(14.2)\end{array}$ \\
\hline \multicolumn{4}{|l|}{ Prostate Cancer Therapy } \\
\hline Androgen Deprivation Therapy: $\mathrm{n}(\%)$ & $14(45.1)$ & $22(68.7)$ & $\begin{array}{l}36 \\
(57.1)\end{array}$ \\
\hline \multicolumn{4}{|l|}{ Radiotherapy } \\
\hline EBRT & $23(74.1)$ & $26(81.3)$ & $\begin{array}{l}49 \\
(77.7)\end{array}$ \\
\hline BT & $8(25.8)$ & $6(19.4)$ & $\begin{array}{l}14 \\
(22.2)\end{array}$ \\
\hline \multicolumn{4}{|l|}{ EBRT Dose: $\mathrm{n}(\%)$} \\
\hline 55 Gy & 0 & $1(3.1)$ & $\begin{array}{l}1 \\
(1.5)\end{array}$ \\
\hline
\end{tabular}




\begin{tabular}{|c|c|c|c|}
\hline & SMaRT Group n = 31 & CAU Group $n=32$ & $\begin{array}{l}\text { Total } \\
(\mathrm{N}= \\
63)\end{array}$ \\
\hline 74 Gy & $19(61.2)$ & $23(71.8)$ & $\begin{array}{l}42 \\
(66.6)\end{array}$ \\
\hline$\geq 76$ Gy & $1(3.2)$ & $2(6.2)$ & $\begin{array}{l}2 \\
(3.1)\end{array}$ \\
\hline Missing dose data & $11(35.4)$ & $6(18.7)$ & $\begin{array}{l}17 \\
(26.9)\end{array}$ \\
\hline \multicolumn{4}{|l|}{ EBRT Fraction: n(\%) } \\
\hline 20 & 0 & $1(3.1)$ & $\begin{array}{l}1 \\
(1.5)\end{array}$ \\
\hline 35 & $1(3.2)$ & 0 & $\begin{array}{l}1 \\
(1.5)\end{array}$ \\
\hline 37 & 19(61.2) & $25(78.1)$ & $\begin{array}{l}44 \\
(69.8)\end{array}$ \\
\hline Missing & $11(35.4)$ & $6(18.75)$ & $\begin{array}{l}17 \\
(26.9)\end{array}$ \\
\hline \multicolumn{4}{|l|}{ Time since EBRT (months): $\mathrm{n} \%$} \\
\hline $3-4$ & $2(6.4)$ & $6(18.7)$ & $\begin{array}{l}8 \\
(1.5)\end{array}$ \\
\hline $5-6$ & $13(41.9)$ & $10(31.2)$ & $\begin{array}{l}23 \\
(36.5)\end{array}$ \\
\hline $7-8$ & $4(12.9)$ & $5(15.6)$ & $\begin{array}{l}9 \\
(14.2)\end{array}$ \\
\hline $9-10$ & $4(12.9)$ & $5(15.6)$ & $\begin{array}{l}9 \\
(14.2)\end{array}$ \\
\hline \multicolumn{4}{|c|}{ Time since Brachytherapy treatment (months): $n \%$} \\
\hline $4-5$ & $3(9.6)$ & 0 & $\begin{array}{l}3 \\
(4.7)\end{array}$ \\
\hline $6-7$ & $2(6.4)$ & $4(12.5)$ & $\begin{array}{l}6 \\
(9.5)\end{array}$ \\
\hline $8-10$ & $3(9.6)$ & $2(6.2)$ & $\begin{array}{l}5 \\
(7.9)\end{array}$ \\
\hline Taking Medication for LUTs: $\mathrm{n}(\%)$ & $16(51.6)$ & $19(59.3)$ & $\begin{array}{l}34 \\
(53.9)\end{array}$ \\
\hline Alpha blocker (Tamsulosin) & $15(48.3)$ & $18(56.2)$ & $\begin{array}{l}33 \\
(52.3)\end{array}$ \\
\hline Anti-muscarinic (Solifenacin) & $1(3.2)$ & $1(3.1)$ & $\begin{array}{l}2 \\
(3.1)\end{array}$ \\
\hline
\end{tabular}




\begin{tabular}{|c|c|c|c|}
\hline & SMaRT Group n = 31 & CAU Group $n=32$ & $\begin{array}{l}\text { Total } \\
(\mathrm{N}= \\
63)\end{array}$ \\
\hline \multicolumn{4}{|c|}{$\begin{array}{l}\text { SD = Standard Deviation; Gy = Gray, QR = Inter Quartile Range; EIMD = English Index of Multiple } \\
\text { Deprivation, EBRT = External Beam Radiation Therapy, LUTS = Lower urinary tract symptoms }\end{array}$} \\
\hline IPSS = International Prostate Symptom Scale & & & \\
\hline
\end{tabular}

Box plots (Fig. 2) illustrate a decrease in IPSS scores for both groups from T1 to T2 and T3; there was a trend for reduction in IPSS with SMaRT at both T2 and T3 time points, but it was not significant which may be partly due to the small sample size. However, there was a large overlap in observed values between the groups. We found no significant differences in our primary outcome between the SMaRT and care-as-usual groups in scores on the IPSS at 3 or 6 months even when adjusted for pre-intervention IPSS baseline scores and adjustment of radiotherapy type (Table 4). 
Table 4

Primary and Secondary Outcome scores between baseline and 3 and 6 months with adjusted change scores.

\begin{tabular}{|c|c|c|c|c|c|c|c|}
\hline Baseline & $\begin{array}{l}3 \\
\text { months }\end{array}$ & Change & $\begin{array}{l}\text { Adjusted } \\
\text { difference } \\
\text { * }\end{array}$ & $\begin{array}{l}\mathrm{p}- \\
\text { value }\end{array}$ & $\begin{array}{l}6 \\
\text { months }\end{array}$ & Change & $\begin{array}{l}\text { Adjusted } \\
\text { difference } \\
\star\end{array}$ \\
\hline
\end{tabular}

IPSS

\begin{tabular}{|c|c|c|c|c|c|c|c|c|c|}
\hline CAU & $\begin{array}{l}13.9 \\
(5.1)\end{array}$ & $\begin{array}{l}10.8 \\
(6.1)\end{array}$ & $\begin{array}{l}-3.1 \\
(-4.9 \text { to } \\
-1.3)\end{array}$ & & & $\begin{array}{l}11.0 \\
(6.1)\end{array}$ & $\begin{array}{l}-2.6 \\
(-4.6 \text { to } \\
-0.6)\end{array}$ & & \\
\hline SMaRT & $\begin{array}{l}13.2 \\
(4.0)\end{array}$ & $\begin{array}{l}8.6 \\
(4.3)\end{array}$ & $\begin{array}{l}-5.0 \\
(-6.5 \text { to } \\
-3.4)\end{array}$ & $\begin{array}{l}-2.1(-4.2 \\
\text { to } 0.1)\end{array}$ & 0.066 & $\begin{array}{l}8.7 \\
(4.7)\end{array}$ & $\begin{array}{l}-4.8 \\
(-6.7 \text { to } \\
-3.0)\end{array}$ & $\begin{array}{l}-2.5(-5.0 \\
\text { to } 0.0)\end{array}$ & 0.054 \\
\hline
\end{tabular}

ICS Voiding symptoms

\begin{tabular}{|c|c|c|c|c|c|c|c|c|c|}
\hline CAU & $5.6(2.7)$ & $\begin{array}{l}4.9 \\
(3.1)\end{array}$ & $\begin{array}{l}-0.8 \\
(-1.3 \text { to } \\
-0.2)\end{array}$ & & & $\begin{array}{l}4.6 \\
(2.4)\end{array}$ & $\begin{array}{l}-0.9 \\
(-1.5 \text { to } \\
-0.3)\end{array}$ & & \\
\hline SMaRT & $5.5(2.7)$ & $\begin{array}{l}3.9 \\
(2.0)\end{array}$ & $\begin{array}{l}-1.9 \\
(-2.6 \text { to } \\
-1.1)\end{array}$ & $\begin{array}{l}-1.1(-2.0 \\
\text { to }-0.2)\end{array}$ & 0.017 & $\begin{array}{l}4.3 \\
(2.8)\end{array}$ & $\begin{array}{l}-1.3 \\
(-2.2 \text { to } \\
-0.3)\end{array}$ & $\begin{array}{l}-0.3(-1.3 \\
\text { to } 0.7)\end{array}$ & 0.521 \\
\hline
\end{tabular}

ICS Incontinence symptoms

\begin{tabular}{|c|c|c|c|c|c|c|c|c|c|}
\hline CAU & $2.8(1.9)$ & $\begin{array}{l}3.2 \\
(2.1)\end{array}$ & $\begin{array}{l}0.5 \\
(-0.2 \text { to } \\
1.2)\end{array}$ & & & $\begin{array}{l}3.1 \\
(2.5)\end{array}$ & $\begin{array}{l}0.3 \\
(-0.4 \text { to } \\
1.0)\end{array}$ & & \\
\hline SMaRT & $3.4(2.2)$ & $\begin{array}{l}2.7 \\
(1.5)\end{array}$ & $\begin{array}{l}-0.9 \\
(-1.6 \text { to } \\
-0.2)\end{array}$ & $\begin{array}{l}-1.0(-1.8 \\
\text { to }-0.1)\end{array}$ & 0.029 & $\begin{array}{l}2.7 \\
(1.6)\end{array}$ & $\begin{array}{l}-0.9 \\
(-1.9 \text { to } \\
-0.1)\end{array}$ & $\begin{array}{l}-0.9(-1.9 \\
\text { to } 0.1)\end{array}$ & 0.073 \\
\hline
\end{tabular}

\section{EORTC25 Urinary domain}

\begin{tabular}{|c|c|c|c|c|c|c|c|c|c|}
\hline CAU & $\begin{array}{l}27.7 \\
(15.6)\end{array}$ & $\begin{array}{l}22.3 \\
(17.9)\end{array}$ & $\begin{array}{l}-4.9 \\
(-9.3 \text { to } \\
-0.6)\end{array}$ & & & $\begin{array}{l}21.3 \\
(16.3)\end{array}$ & $\begin{array}{l}-6.6 \\
(-11.6 \\
\text { to }-1.6)\end{array}$ & & \\
\hline SMaRT & $\begin{array}{l}27.3 \\
(15.9)\end{array}$ & $\begin{array}{l}20.8 \\
(14.6)\end{array}$ & $\begin{array}{l}-7.1 \\
(-11.2 \\
\text { to }-3.0)\end{array}$ & $\begin{array}{l}-1.9(-7.5 \\
\text { to } 3.8)\end{array}$ & 0.506 & $\begin{array}{l}18.5 \\
(15.0)\end{array}$ & $\begin{array}{l}-9.7 \\
(-14.9 \\
\text { to }-4.5)\end{array}$ & $\begin{array}{l}-3.7(-10.0 \\
\text { to } 2.6)\end{array}$ & 0.245 \\
\hline
\end{tabular}

\section{EORTC30 Emotional functioning domain}

\begin{tabular}{|c|c|c|c|c|c|c|c|c|c|}
\hline CAU & $\begin{array}{l}84.7 \\
(14.4)\end{array}$ & $\begin{array}{l}87.7 \\
(15.2)\end{array}$ & $\begin{array}{l}2.9 \\
(-1.8 \text { to } \\
7.5)\end{array}$ & & & $\begin{array}{l}87.6 \\
(14.9)\end{array}$ & $\begin{array}{l}2.4 \\
(-1.4 \text { to } \\
6.2)\end{array}$ & & \\
\hline SMaRT & $\begin{array}{l}85.7 \\
(17.0)\end{array}$ & $\begin{array}{l}83.3 \\
(18.2)\end{array}$ & $\begin{array}{l}-2.5 \\
(-7.8 \text { to } \\
2.7)\end{array}$ & $\begin{array}{l}-5.0(-11.7 \\
\text { to } 1.8)\end{array}$ & 0.147 & $\begin{array}{l}87.7 \\
(13.6)\end{array}$ & $\begin{array}{l}1.4 \\
(-1.9 \text { to } \\
4.8)\end{array}$ & $\begin{array}{l}-0.3(-5.1 \\
\text { to } 4.5)\end{array}$ & 0.902 \\
\hline
\end{tabular}

\section{SESCI Performing daily activities}




\begin{tabular}{|c|c|c|c|c|c|c|c|c|c|}
\hline & Baseline & $\begin{array}{l}3 \\
\text { months }\end{array}$ & Change & $\begin{array}{l}\text { Adjusted } \\
\text { difference } \\
\star\end{array}$ & $\begin{array}{l}\mathrm{p}- \\
\text { value }\end{array}$ & $\begin{array}{l}6 \\
\text { months }\end{array}$ & Change & $\begin{array}{l}\text { Adjusted } \\
\text { difference } \\
\star\end{array}$ & $\begin{array}{l}\text { p- } \\
\text { value }\end{array}$ \\
\hline CAU & $\begin{array}{l}89.7 \\
(16.4)\end{array}$ & $\begin{array}{l}83.3 \\
(25.3)\end{array}$ & $\begin{array}{l}-3.9 \\
(-10.7 \\
\text { to } 2.9)\end{array}$ & & & $\begin{array}{l}87.4 \\
(20.9)\end{array}$ & $\begin{array}{l}-1.2 \\
(-6.6 \text { to } \\
4.2)\end{array}$ & & \\
\hline SMaRT & $\begin{array}{l}88.3 \\
(17.9)\end{array}$ & $\begin{array}{l}85.7 \\
(20.5)\end{array}$ & $\begin{array}{l}-3.3 \\
(-10.8 \\
\text { to } 4.1)\end{array}$ & $\begin{array}{l}0.6(-9.1 \\
\text { to } 10.3)\end{array}$ & 0.901 & $\begin{array}{l}86.1 \\
(21.6)\end{array}$ & $\begin{array}{l}-4.5 \\
(-8.9 \text { to } \\
-0.2)\end{array}$ & $\begin{array}{l}-3.5(-10.4 \\
\text { to } 3.5)\end{array}$ & 0.324 \\
\hline \multicolumn{10}{|c|}{ SESCI Coping with symptoms } \\
\hline CAU & $\begin{array}{l}77.8 \\
(19.0)\end{array}$ & $\begin{array}{l}78.0 \\
(20.8)\end{array}$ & $\begin{array}{l}-4.8 \\
(-13.5 \\
\text { to } 3.9)\end{array}$ & & & $\begin{array}{l}80.9 \\
(17.3)\end{array}$ & $\begin{array}{l}1.9 \\
(-4.0 \text { to } \\
7.7)\end{array}$ & & \\
\hline SMaRT & $\begin{array}{l}74.3 \\
(18.6)\end{array}$ & $\begin{array}{l}77.5 \\
(17.5)\end{array}$ & $\begin{array}{l}2.8 \\
(-1.8 \text { to } \\
7.3)\end{array}$ & $\begin{array}{l}5.4(-4.5 \\
\text { to } 15.0)\end{array}$ & 0.274 & $\begin{array}{l}83.2 \\
(15.5)\end{array}$ & $\begin{array}{l}7.0(3.4 \\
\text { to } \\
10.7)\end{array}$ & $\begin{array}{l}4.3(-2.2 \\
\text { to } 10.8)\end{array}$ & 0.192 \\
\hline \multicolumn{10}{|c|}{ SESCI Managing symptoms } \\
\hline CAU & $\begin{array}{l}67.1 \\
(21.1)\end{array}$ & $\begin{array}{l}63.0 \\
(24.9)\end{array}$ & $\begin{array}{l}-5.9 \\
(-14.7 \\
\text { to } 2.9)\end{array}$ & & & $\begin{array}{l}66.8 \\
(22.9)\end{array}$ & $\begin{array}{l}-0.1 \\
(-5.6 \text { to } \\
5.5)\end{array}$ & & \\
\hline SMaRT & $\begin{array}{l}58.6 \\
(22.5)\end{array}$ & $\begin{array}{l}72.5 \\
(20.6)\end{array}$ & $\begin{array}{l}11.0 \\
(3.2 \text { to } \\
18.9)\end{array}$ & $\begin{array}{l}13.5(2.5 \\
\text { to } 24.4)\end{array}$ & 0.017 & $\begin{array}{l}71.0 \\
(22.6)\end{array}$ & $\begin{array}{l}8.8(0.9 \\
\text { to } \\
16.6)\end{array}$ & $\begin{array}{l}7.0(-2.2 \\
\text { to } 16.0)\end{array}$ & 0.133 \\
\hline \multicolumn{10}{|c|}{ *adjusting for baseline IPSS scores and Radiotherapy (EBRT vs BT) which were included as covariates. } \\
\hline $\begin{array}{l}\text { Abbrev } \\
\text { Prostat }\end{array}$ & s: CAU, & e as u & ; SMaRT, & $\begin{array}{l}\text { elf-Manag } \\
\text { ontinence }\end{array}$ & nt sup & rt After & iotherap & & \\
\hline
\end{tabular}

At 3 months, ICS voiding symptoms had improved by -1.9 points (95\% Cl:-2.6 to-1.1) in the SMaRT group and by -0.8 points ( $95 \% \mathrm{Cl}-1.3$ to- 0.2 ) in the care-as-usual group, a significant adjusted difference of -1.1 points (-2.0 to $-0.2)$ favouring SMaRT ( $p=0.017$ Table 4$)$. ICS voiding symptoms did not differ significantly at 6 months. At 3 months, ICS incontinence symptoms had improved by -0.9 points (- -1.6 to -0.2$)$ in the SMaRT group and deteriorated by 0.5 points ( -0.2 to 1.2$)$ in the care-as-usual group, a significant adjusted difference of -1.0 points $(-1.8$ to -0.1$)$ favouring SMaRT $(p=0.029$ Table 4$)$. ICS incontinence symptoms did not differ significantly at 6 months. There were no observed differences in quality-of-life (EORTC QLQ-C30) or urinary domain scores (EORTC QLQ-PR25) between groups.

Self-Efficacy for managing symptoms measured by the SESCl improved by 11.0 points ( $95 \% \mathrm{Cl}: 3.2$ to 18.9 ) in the SMaRT group and decreased by -5.9 points (-14.7 to 2.9$)$ in the care-as-usual group, a significant adjusted difference of 13.9 points ( 2.5 to 24.4 ) favouring the SMaRT group $(p=0.017)$ (Table 4). Self-efficacy for managing symptoms did not differ significantly between the groups at 6 months. We noted no significant differences between the care-as-usual and SMaRT groups in self-efficacy for performing daily activities or selfefficacy for coping with symptoms at either 3 months or 6 months. 


\section{Discussion}

We found that self-management after radiotherapy intervention (SMaRT) had no significant difference on IPSS outcomes in men who had received radiotherapy for PCa, compared to care-as-usual, at 3 and 6 months, but did provide significant differences in domain specific urinary symptoms on ICS voiding and incontinence at 3 months. Our intervention improved urinary symptoms in ICS voiding by -1.9 and when adjusted for baseline scores a change of -1.1 and urinary incontinence by -0.9 . As secondary outcomes we observed significant benefit in reported self-efficacy for men in managing symptoms at 3 months with a 13.5 (2.5 to 24.4) adjusted point difference in the SMaRT group compared to -5.9 (-14.7 to 2.9) care-as-usual. The intervention effect was not able to be sustained beyond 3 months as seen in the follow up scores where there was little difference between groups.

Contrary to our findings, Dieperink et al.(20) in their study of multidisciplinary rehabilitation, found a 5.8 point (Cohen's $d=0.40 ; p 0.011$ ) difference in urinary sum scores for irritative symptoms between those receiving the intervention and care-as-usual recorded at 6 months post radiotherapy. In this study the usual care group had 1 physician visit face to face 4 weeks after radiotherapy whereas our care-as-usual group saw the physician at 6 months and had ongoing contact with a CNS. Despite this difference the change in urinary scores were not at the same level as that found by Dieperink (20) or in our feasibility study (25). The distinct difference between these studies is the intervention intensity, SMaRT was primarily group based and may not have provided the individualised approach provided by Dieperink (20) in the face-to-face multidisciplinary rehabilitation setting. This dosing effect is important in PFME as variation in delivery such as the muscle targeted intensity of the programme and the position in which pelvic floor muscle contraction is taught, are influential factors and contribute to variation in intervention outcomes (33). There is a need to focus more on the mechanistic science underpinning interventions for managing pelvic radiotherapy late effects. Damage to pelvic floor vasculature and fibrosis all contribute to lower urinary tract symptoms (18). One retrospective study of men with PCa who underwent MRI before and after EBRT or BT showed significant reductions in urethral length, increased signal intensity of the obturator internus muscle and peri-urethral part of the levator ani, suggestive of fibrotic changes (16). Diepernick et al.(34) in a follow-on study found that that pelvic floor muscle strength of men in their intervention study diminished over the 3 years post intervention but that men still had better LUTS than men in their control group.

In cancer populations, the evidence for self-management and lifestyle interventions is growing $(24,35)$ but is not consistent and negative trends in psychological distress for instance, have also been reported in some systematic reviews (23). Furthermore, whilst a recent systematic review (36) has classified the important components of benign LUTS self-management, the active components or behavioural interventions that contribute to these are far from clear. Skolarus et al.(37) reported a RCT of a self-management programme for long-term prostate cancer survivors and found no significant differences between intervention and control groups. However, like our study coping appraisal was higher $(2.8 v s 2.6 p=0.02)$ in men who had received the intervention. This highlights the problems with heterogeneity of the needs of men, specificity of intervention and how best to measure the clinical significance of any benefits of self-management i.e., is it the symptoms that are the primary aim or the self-efficacy? In our study, men had a high level of self-efficacy across domains from the start of the study but clearly the participant modelling and information helped them manage symptoms and feel more confident post treatment. 


\section{Strengths and limitations}

A strength of SMaRT was we targeted men with long-term symptoms 3-6 months from completion of treatment, compared to other self-management intervention studies that occur during treatment. Differences we found may reflect a more difficult population that as urinary symptoms continue after radiotherapy, they can become more intractable (18). Men who have brachytherapy are much more likely to have issues with voiding due to swelling and inflammation which are probably less affected by PFME, however, this was adjusted for in the analysis. A limitation of our study is that we did not use, surface anal electromyography (EMG) to assess men's pelvic floor, or provide ongoing data on pelvic floor changes, or participant diaries to record adherence to PFME. Given EMG assessment is invasive in a group setting, it may have been useful to use it in the one-to-one session with the CNS to assess the effectiveness of the individuals' exercises. Studies of PFME in men with PCa have focused mainly on the surgical setting and have shown that pelvic floor muscle exercises pre- and post-treatment can improve symptom outcomes (38) and this evidence is reflected in NICE UK (39) prostate cancer guidelines. Studies show that men who continue to have LUTS after radiotherapy have significant reductions in quality-oflife (40). In a systematic review of 13 studies, post radiotherapy pelvic floor muscle changes were found to occur between 2 and 26 months after radiation, showing the wide range of individual response in men with PCa (19). Some of this variance may be due to prior LUTS (14), however, we adjusted for this as part of our analysis.

\section{Conclusions}

The study showed that the SMaRT intervention helped men feel more confident in managing symptoms and created small changes in LUTS but was not clinically significant or sustained. Evidence for conservative interventions that augment self-management post pelvic radiotherapy are limited, therefore this RCT provides important evidence that contributes to improving treatment pathways for those living with and beyond prostate cancer. The growing number of men now surviving and requiring long-term symptom management for consequences of PCa has contributed to the growth in supported self-management programs to address longterm survivorship care (41-43) but the outcomes of these studies are varied partly because self-management requires targeted interventions to improve not only self-efficacy but personalised management strategies to improve symptoms. Although the intervention was not effective, some of the elements show promise and that a more targeted one-to-one approach is needed to address the more complex LUTS as a result of radiotherapy.

\section{Declarations}

Acknowledgements: Randomisation was provided by Clinical Trials Research Unit at the University of Leeds. We thank Sean Harry, research fellow for assisting with data collection and Hannah Fairbanks for initial data analysis and all the patients and clinical staff who participated in the project.

Authors Contribution: All authors contributed to this manuscript. SF is principal investigator and lead author of this manuscript. SF and JC-H contributed to the conception, design, data collection and data analysis. SS provided the clinical trial interpretation, AL the statistical analysis and SO provided an oncology perspective. All authors contributed to the manuscript, read and approved the final version.

Funding: This study was funded by a research grant from Dimbleby Cancer Care UK registered charity 247558 
Data availability: The data can be requested by contact the corresponding author. The access will be granted subject to a reasonable request and data sharing agreement.

Code availability: No bespoke software was created.

Ethics approval: The trial received a favourable ethical opinion from the National Research Ethics (UK) registration 10/H1109/55 and the University of Surrey Ethics Committee. It was registered with the National Institute of Health, UK Clinical Research Network ID 9433, and with ISRCTN Registration Number 20069765.

Consent to participate: All participates in the research were invited either by a member of the clinical team or through a letter from their clinical oncologist during or after radiotherapy treatment. Patient information sheets were provided to participants and patient written consent obtained.

Consent for publication: Not applicable

Conflict of interest: SF is a trustee of PCUK and chair of NCRI late consequences research group. No other authors declare a conflict of interest.

\section{References}

1. CancerResearchUK. Prostate Cancer survival statistics London2015-17 [Available from: https://www.cancerresearchuk.org/health-professional/cancer-statistics/statistics-by-cancer-type/prostatecancer

2. Bray F, Ferlay J, Soerjomataram I, Siegel RL, Torre LA, Jemal A (2018) Global cancer statistics 2018 : GLOBOCAN estimates of incidence and mortality worldwide for 36 cancers in 185 countries. CA Cancer J Clin 68(6):394-424

3. Hoffman KE, Penson DF, Zhao Z, Huang L-C, Conwill R, Laviana AA et al (2020) Patient-Reported Outcomes Through 5 Years for Active Surveillance, Surgery, Brachytherapy, or External Beam Radiation With or Without Androgen Deprivation Therapy for Localized Prostate Cancer. JAMA 323(2):149-163

4. Mazariego CG, Egger S, King MT, Juraskova I, Woo H, Berry M et al (2020) Fifteen year quality of life outcomes in men with localised prostate cancer: population based Australian prospective study. BMJ 371:m3503

5. Lagergren P, Schandl A, Aaronson NK, Adami HO, de Lorenzo F, Denis L et al (2019) Cancer survivorship: an integral part of Europe's research agenda. Mol Oncol 13(3):624-635

6. Carlsson S, Drevin L, Loeb S, Widmark A, Lissbrant IF, Robinson D et al (2016) Population-based study of long-term functional outcomes after prostate cancer treatment. BJU Int 117(6B):E36-E45

7. Kim S, Moore DF, Shih W, Lin Y, Li H, Shao YH et al (2013) Severe genitourinary toxicity following radiation therapy for prostate cancer-how long does it last? J Urol 189(1):116-121

8. Wilding S, Downing A, Wright P, Selby P, Watson E, Wagland R et al (2019) Cancer-related symptoms, mental well-being, and psychological distress in men diagnosed with prostate cancer treated with androgen deprivation therapy. Qual Life Res 28(10):2741-2751

9. Paterson C, Jones M, Rattray J, Lauder W (2013) Exploring the relationship between coping, social support and health-related quality of life for prostate cancer survivors: a review of the literature. Eur $\mathrm{J}$ Oncol Nurs 
17(6):750-759

10. Liberman D, Mehus B, Elliott SP (2014) Urinary adverse effects of pelvic radiotherapy. Transl Androl Urol $3(2): 186-195$

11. Faithfull S, Lemanska A, Aslet P, Bhatt N, Coe J, Drudge-Coates L et al (2015) Integrative review on the noninvasive management of lower urinary tract symptoms in men following treatments for pelvic malignancies. Int J Clin Pract 69(10):1184-1208

12. Lemanska A, Dearnaley DP, Jena R, Sydes MR, Faithfull S. Older Age, Early Symptoms and Physical Function are Associated with the Severity of Late Symptom Clusters for Men Undergoing Radiotherapy for Prostate Cancer. Clin Oncol (R Coll Radiol). 2018

13. Chen RC, Clark JA, Talcott JA (2009) Individualizing quality-of-life outcomes reporting: how localized prostate cancer treatments affect patients with different levels of baseline urinary, bowel, and sexual function. Journal Of Clinical Oncology: Official Journal Of The American Society Of Clinical Oncology 27(24):3916-3922

14. Groom N, Tsang Y, Lowe G, Hoskin P. Risk factors for urethral stricture following external beam radiotherapy and HDR brachytherapy for prostate cancer. Brachytherapy. 2020

15. Tree A, Khoo V (2009) Treatment of early prostate cancer: radiotherapy, including brachytherapy. Trends in Urology Gynaecology Sexual Health 14(5):18-23

16. Marigliano C, Donati OF, Vargas HA, Akin O, Goldman DA, Eastham JA et al (2013) MRI findings of radiationinduced changes in the urethra and periurethral tissues after treatment for prostate cancer. Eur $\mathrm{J}$ Radiol 82(12):e775-e781

17. Awad MA, Gaither TW, Osterberg EC, Murphy GP, Baradaran N, Breyer BN (2018) Prostate cancer radiation and urethral strictures: a systematic review and meta-analysis. Prostate Cancer Prostatic Dis 21(2):168-174

18. Bosch R, McCloskey K, Bahl A, Arlandis S, Ockrim J, Weiss J et al (2020) Can radiation-induced lower urinary tract disease be ameliorated in patients treated for pelvic organ cancer: ICI-RS 2019? Neurourol Urodyn 39(Suppl 3):S148-S155

19. Bernard S, Ouellet MP, Moffet H, Roy JS, Dumoulin C (2016) Effects of radiation therapy on the structure and function of the pelvic floor muscles of patients with cancer in the pelvic area: a systematic review. J Cancer Surviv 10(2):351-362

20. Dieperink K, Johansen C, Hansen S, Wagner L, Anderson K, Minet L et al (2013) The effects of multidisciplinary rehabilitation: RePCa- a randomnised study among primary prostate cancer patients. $\mathrm{Br} \mathrm{J}$ Cancer 109:3005-3013

21. de Longh A, Fagan P, Fenner J, Kidd L. A practical guide to self-management support. 90 Long Acre, London, WC2E 9RA: The Health Foundation; 2015. Contract No.: ISBN 978-1-906481-74-4

22. Cuthbert CA, Farragher JF, Hemmelgarn BR, Ding Q, McKinnon GP, Cheung WY (2019) Self-management interventions for cancer survivors: A systematic review and evaluation of intervention content and theories. Psycho-Oncology 28(11):2119-2140

23. Boland L, Bennett K, Connolly D (2018) Self-management interventions for cancer survivors: a systematic review. Support Care Cancer 26(5):1585-1595

24. Kim SH, Kim K, Mayer DK (2017) Self-Management Intervention for Adult Cancer Survivors After Treatment: A Systematic Review and Meta-Analysis. Oncol Nurs Forum 44(6):719-728

Page $19 / 22$ 
25. Faithfull S, Cockle-Hearne J, Khoo V (2011) Self-management after prostate cancer treatment: evaluating the feasibility of providing a cognitive and behavioural programme for lower urinary tract symptoms. BJU Int 107(5):783-790

26. Lorig KR, Holman H (2003) Self-management education: history, definition, outcomes, and mechanisms. Ann Behav Med 26(1):1-7

27. Foster C, Breckons M, Cotterell P, Barbosa D, Calman L, Corner J et al (2015) Cancer survivors' self-efficacy to self-manage in the year following primary treatment. J Cancer Surviv 9(1):11-19

28. Cockle-Hearne J, Cooke D, Faithfull S (2016) Developing peer support in film for cancer self-management: what do men want other men to know? Support Care Cancer 24(4):1625-1631

29. Barry MJ, Fowler Jnr FJ, O'Leary MP, Bruskewitch RC, Holtgrewe HL, Mebust WK et al (1992) The American Urological Association Symptom Index for Benign Prostatic Hyperplasia: The Measurement Committee of the American Urological Association. J Urol 148:1549-1557

30. Donovan JL, Peters TJ, Abrams P, Brookess ST, de la Rosette JJMCH, Schafer W (2000) Scoring the Short Form ICSmaleSF Questionnaire: International Continence Society. J Urol 164(6):1948-1955

31. Whistance RN, Conroy T, Chie W, Costantini A, Sezer O, Koller M et al. Clinical and psychometric validation of the EORTC QLQ-CR29 questionnaire module to assess health-related quality of life in patients with colorectal cancer. European Journal Of Cancer (Oxford, England: 1990). 2009;45(17):3017-26

32. Campbell LC, Keefe FJ, McKee DC, Edwards CL, Herman SH, Johnson LE et al (2004) Prostate cancer in African Americans: relationship of patient and partner self-efficacy to quality of life. J Pain Symptom Manage 28(5):433-444

33. Hall LM, Aljuraifani R, Hodges PW (2018) Design of programs to train pelvic floor muscles in men with urinary dysfunction: Systematic review. Neurourol Urodyn 37(7):2053-2087

34. Dieperink KB, Hansen S, Wagner L, Minet LR, Hansen O. Long-term follow-up 3 years after a randomized rehabilitation study among radiated prostate cancer survivors. J Cancer Surviv. 2020

35. Howell D, Harth T, Brown J, Bennett C, Boyko S (2017) Self-management education interventions for patients with cancer: a systematic review. Support Care Cancer 25(4):1323-1355

36. Albarqouni L, Sanders S, Clark J, Tikkinen KAO, Glasziou P (2021) Self-Management for Men With Lower Urinary Tract Symptoms: A Systematic Review and Meta-Analysis. Ann Fam Med 19(2):157-167

37. Skolarus TA, Metreger T, Wittmann D, Hwang S, Kim HM, Grubb RL 3 (2019) Self-Management in Long-Term Prostate Cancer Survivors: A Randomized, Controlled Trial. J Clin Oncol 37(15):1326-1335 rd, et al.

38. Zhang A, Fu A, Moore S, Zhu H, Strauss G, Kresevic D et al. Is a behavioral treatment for urinary incontinence beneficial to prostate cancer survivors as a follow-up care? Journal of Cancer Survivorship. 2016

39. NICE (2019) Prostate cancer: diagnosis and management. National Institute for Clinical Evidence, London, ng1319 May 2019. Contract No.

40. Downing A, Wright P, Hounsome L, Selby P, Wilding S, Watson E et al (2019) Quality of life in men living with advanced and localised prostate cancer in the UK: a population-based study. Lancet Oncol 20(3):436-447

41. Frankland J, Brodie H, Cooke D, Foster C, Foster R, Gage H et al (2019) Follow-up care after treatment for prostate cancer: evaluation of a supported self-management and remote surveillance programme. BMC Cancer 19(1):368 
42. Skolarus TA, Wittmann D, Hawley ST (2017) Enhancing prostate cancer survivorship care through selfmanagement. Urol Oncol 35(9):564-568

43. Bowler M, Dehek R, Thomas E, Ngo K, Grose L (2019) Evaluating the Impact of Post-Treatment SelfManagement Guidelines for Prostate Cancer Survivors. J Med Imaging Radiat Sci 50(3):398-407

\section{Figures}

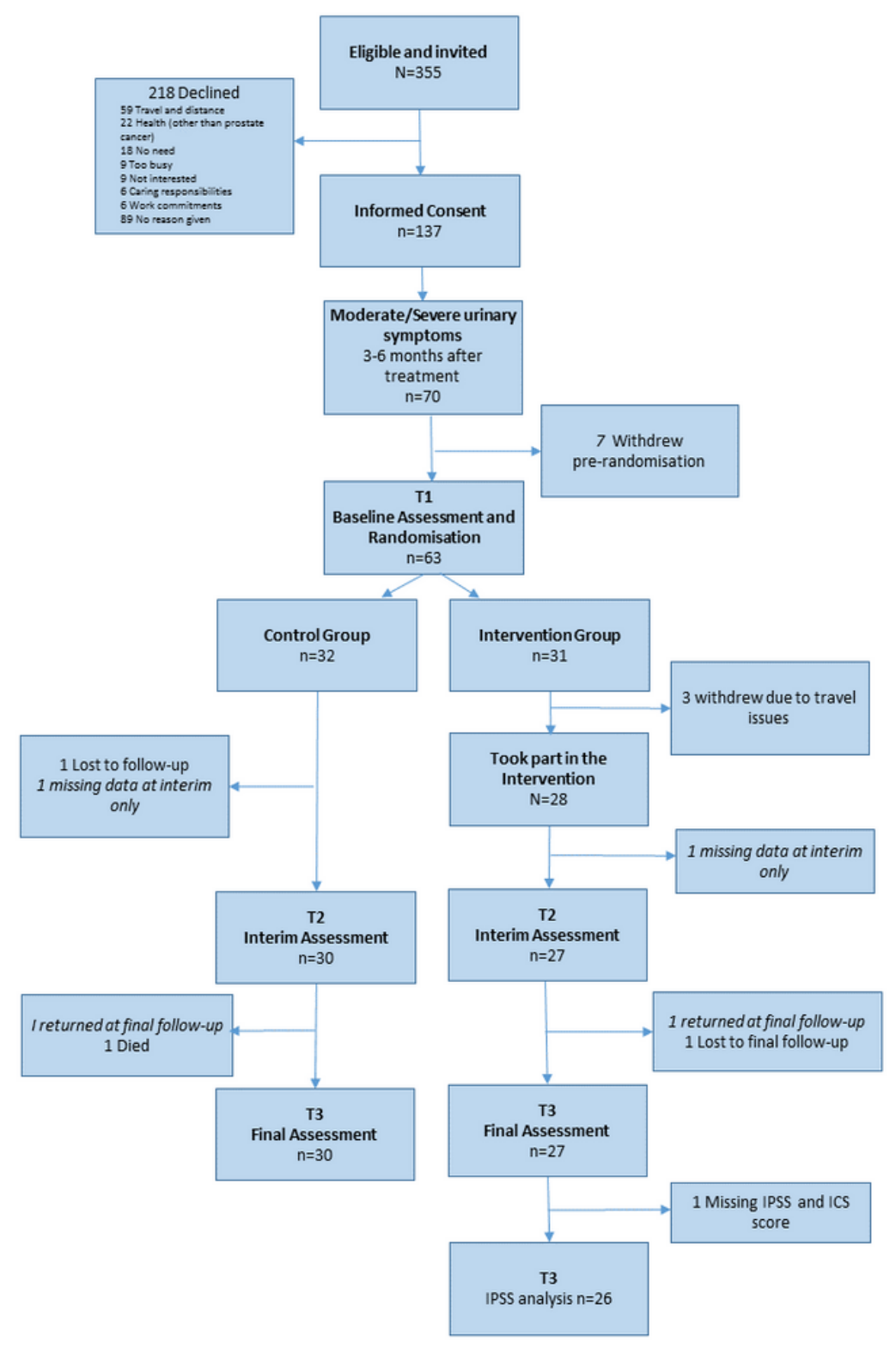

Figure 1 
CONSORT diagram of recruitment and study flow

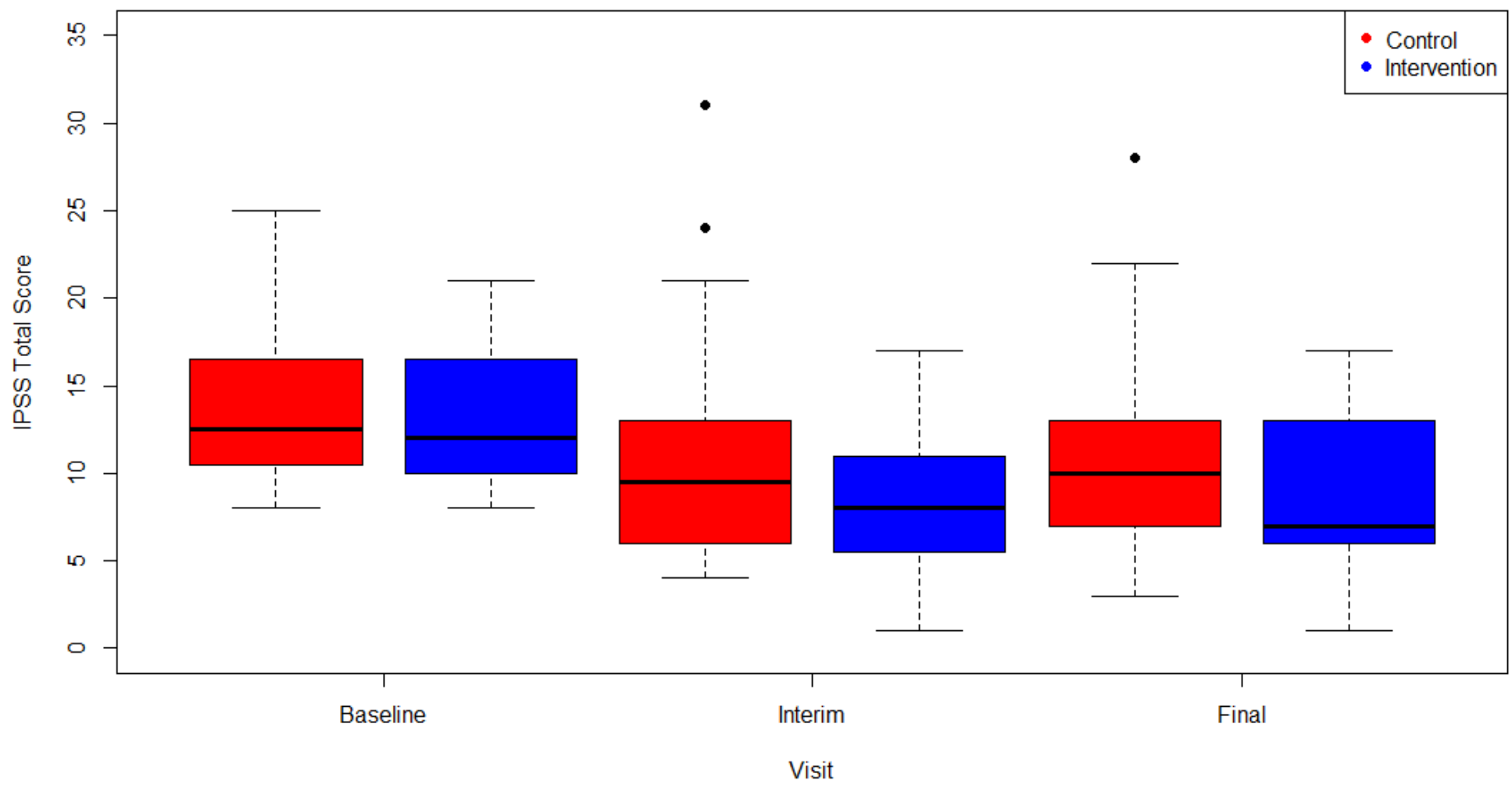

Figure 2

Distribution of IPSS Total Scores at each time point for Self-Management support After Radiotherapy (SMaRT Intervention) and care as usual (CAU - Control) Groups 